\title{
Erratum to: AST classification of proximal humeral fractures: introduction and interobserver reliability assessment
}

Christian Cuny · Cedric Baumann · Julien Mayer •

Didier Guignand · M'barek Irrazi • Aboubekr Berrichi •

Nicolas Ionescu $\cdot$ Francis Guillemin

Published online: 22 February 2013

(C) Springer-Verlag France 2013

Erratum to: Eur J Orthop Surg Traumatol (2013)

23:35-40

DOI 10.1007/s00590-011-0916-5

Unfortunately, critical information on Figs. 8 and 9 was missing in the original article. Hereby, the correct figures are published and we apologize for the inconvenience.

The online version of the original article can be found under doi:10.1007/s00590-011-0916-5.

\footnotetext{
C. Cuny $(\bowtie) \cdot$ J. Mayer · D. Guignand · M. Irrazi · A. Berrichi ·

N. Ionescu

Department of Orthopaedics and Traumatology,

CHR Metz Bon-Secours, 57038 Metz Cedex, France

e-mail: c.cuny@chr-metz-thionville.fr

C. Baumann · F. Guillemin

Department of Clinical Epidemiology, CHU Nancy,

Rue du Morvan, 54511 Vandoeuvre-lès-Nancy, France
}

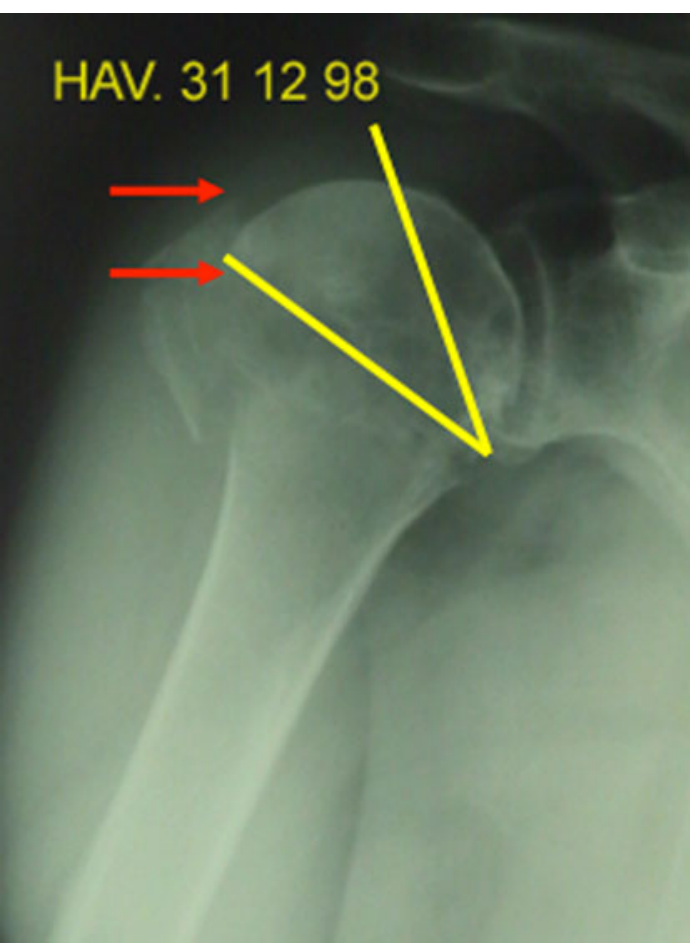

Fig. 8 "A2- $40^{\circ}-10 \mathrm{~mm}$ " (Articular impacted with $40^{\circ}$ of cephalic tilting and $10 \mathrm{~mm}$ of linear displacement) 


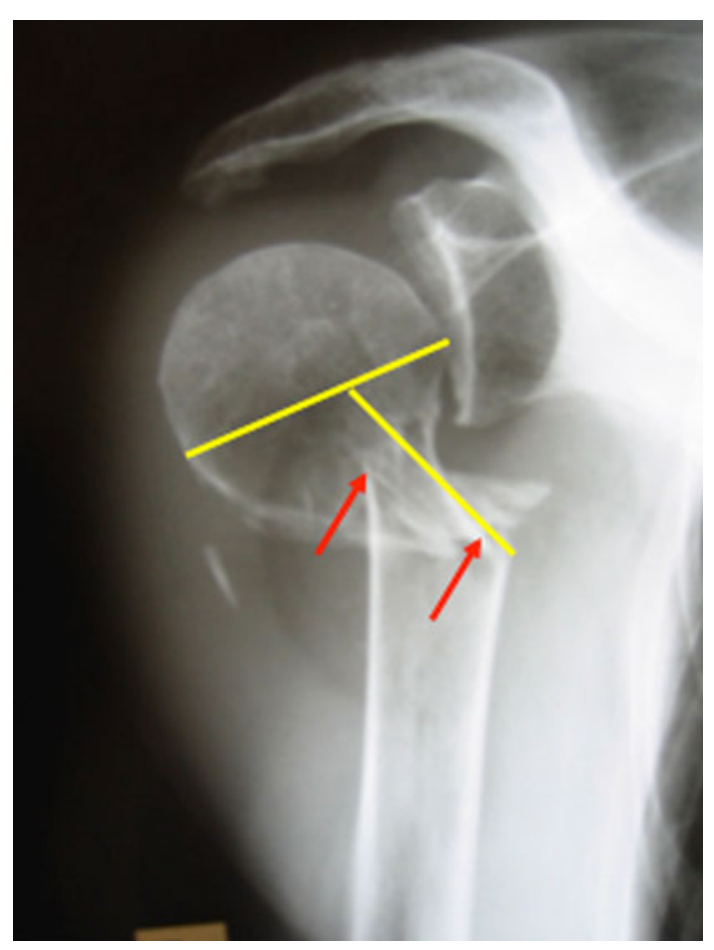

Fig. 9 "S- $60^{\circ}-20 \mathrm{~mm}$ " (Surgical neck with an angle of $60^{\circ}$ and $20 \mathrm{~mm}$ of linear displacement) 